\title{
TEMPERATURE-RELATED PERFORMANCE FACTORS FOR CHEMICAL DEMOLITION AGENTS
}

\begin{abstract}
Soundless chemical demotion agents (SCDAs) are percussion-free alternatives to blasting for rock, concrete, and masonry. They hold great potential for selective demolition of and around historic masonry. Although known to be temperature sensitive, to date their performance has not been quantified in ambient environments below $20^{\circ} \mathrm{C}$. This paper examines 6 large-scale $\left(0.77-1.0 \mathrm{~m}^{3}\right)$ specimens in moderate, ambient temperatures $\left(16.1-19.3^{\circ} \mathrm{C}\right)$. Substantially slower response than that reported by manufacturers was documented. Initial cracking required 25+ hours and continued for 4-8 days. Cracks opened rapidly after Minimum Demolition Time [(MDT) - cumulative cracking around the perimeter reaching $\sim 25 \mathrm{~mm}$ (1 in.)], which was at $42 \mathrm{hr}$ and $70 \mathrm{hr}$, respectively in 16.8 $\mathrm{MPa}$ and $33.1 \mathrm{MPa}$ specimens. Post-MDT, crack-width opening velocities were $0.35-0.96 \mathrm{~mm} / \mathrm{hr}$, approximately $1 / 3^{\text {rd }}$ to $2 / 3^{\text {rds }}$ of pre-MDT velocities. A $0.5^{\circ} \mathrm{C}$ ambient temperature drop delayed MDT by $6.5 \mathrm{hr}$ amongst specimens of the same size and strength. Generally, MDT appeared to correlate with the material strength (irrespective of ambient temperature or specimen size), while TFC was more influenced by ambient temperature. Finally, SCDA reapplication proved effective for incompletely cracked specimens.
\end{abstract}

Keywords: SCDAs, expansive cements, concrete, cracking, masonry conservation, demolition. 


\section{Notation}

TFC = Time to First Crack

$T F M C=$ Time to First Major Crack

$M D T=$ Minimum Demolition Time

$L \quad=$ distance between two holes

$k \quad=$ spacing ratio

$D \quad=$ hole diameter

$d_{i} \quad=$ inner diameter of steel cylinder

$d_{o} \quad=$ outer diameter of steel cylinder

$h \quad=$ height of steel cylinder

$w_{c \max }=$ cumulative maximum crack width

$w_{\text {smax }}=$ single maximum crack width

$l_{m} \quad=$ maximum length of the minor cracks on the top face

$v_{w 1}=$ velocity of cumulative crack width opening in Stage 1

$v_{w 2}=$ velocity of cumulative crack width opening in Stage 2

$w_{\max }=$ final maximum cumulative crack width

$v_{\text {e-all }}=$ overall elongation velocity

$v_{e-p}=$ elongation velocity of crack from the hole to the periphery

$v_{e-b}=$ elongation velocity of crack from the periphery to the block bottom

$v_{r l}=$ velocity of cumulative crack width opening in the first $4 \mathrm{hr}$ in retesting

$v_{r 2}=$ velocity of cumulative crack width opening after $4 \mathrm{hr}$ in retesting 


\section{Introduction}

Expansive cement properties were first identified by Cadlot and Michaelis in the 1890s when investigating ettringite in cement (Candlot, 1890, Candlot, 1906, Michaelis, 1892). Such materials were not, however, marketed until the early 1970s for concrete and rock removal (Gani, 1997). Although not yet used for selective removal of masonry, there is no reason that they cannot be used in that application as well, as the cracking is highly limited and very controllable.

Much of the research to date, however, for these products [typically referred to as Soundless Chemical Demolition Agents (SCDAs)] has focused on their chemistry (Cohen, 1983a, Cohen, 1983b, Cohen et al., 1991, Cohen and Richards, 1982, Neville, 1981), rather than on their mechanical behavior and even less of it has been in actual production-scale samples (irrespective of the surrounding material - rock, concrete, masonry). From an engineering perspective, six main variables have been identified that influence SCDA performance: strength of the surrounding material to be demolished; hole diameter; distance between holes; water/SCDA ratio; mix water temperature, and ambient temperature.

The depth and orientation of the holes also play key roles (Huynh and Laefer, 2009 ). Hole depths of $70-90 \%$ of the sample height have been proposed depending upon the material to be demolished and the SCDA brand (Huynh and Laefer, 2009 , Dexpan, 2016, Bristar, 2016). Significant research has been done on hole diameter and spacing. For example, Gómez and Mura (1984) proposed the correlation $L=k D$, where $L$ is the distance between two holes in the sample, $D$ the hole diameter, and $k$ a spacing ratio dependent upon the material to be demolished. They also proposed $5<k<10$ for 
prestressed concrete, $12<k<18$ for soft rock and concrete, $8<k<12$ for medium hard rock, and $k<10$ for hard rock. However, Gambatese (2003) proposed a dissimilar, and generally more conservative, spacing of $4<k<10$; possibly from the lack of explicit material scaling considerations applied to the small-scale experiments from which the rules were derived. Dowding and Labuz (1982) studied an SCDA in thick-walled, steel cylinders and in rock specimens in the laboratory and the field. They concluded that the expansive pressure was independent of the hole diameter. Conversely, however, they found that hole size strongly impacted demolition time. For example, intact dolomite slabs (0.2-1.0 $\mathrm{m}^{3}$, of a $165 \mathrm{MPa}$ compressive strength) with a $38 \mathrm{~mm}$ hole cracked after $18 \mathrm{hr}$, while the same material with a $12.7 \mathrm{~mm}$ hole required $42 \mathrm{hr}$. Additionally, after $90 \mathrm{hr}$, the maximum single crack width in the $38 \mathrm{~mm}$ hole sample was approximately $40 \%$ of the hole diameter, while that of the $12.7 \mathrm{~mm}$ hole was just $3 \%$ of the hole's diameter.

The maximum obtainable pressure is known to be influenced by the water content, as investigated by Hinze and Brown (1994) who showed an inverse relationship between an SCDA's slurry's water content and the maximum expansive pressure. An approximately $33 \%$ decrease in maximum expansive pressure was recorded at $24 \mathrm{hr}$ when the water content increased from $30 \%$ to $34 \%$ (both within the manufacturer's recommended range). In a similar study, Hinze and Nelson (1996) reduced the slurry's water content to $27.7 \%$ ( $3 \%$ lower than manufacturer's suggestion), which increased the maximum $24 \mathrm{hr}$ expansive pressure by $19.8 \%$ at $35^{\circ} \mathrm{C}$. Moreover, when they replaced half of the SCDA with sand, at an ambient temperature of $35^{\circ} \mathrm{C}$ and water content of $31 \%$, the maximum, expansive pressure at $24 \mathrm{hr}$ was reduced by only $14 \%$ compared to the slurry with no sand. 
Temperature is also known to have a significant influence on the maximum obtainable expansive pressure. In a study by Dowding and Labuz (1982), when the ambient temperature was decreased by $10^{\circ} \mathrm{C}$, the expansive pressure decreased by about $30 \%$ at $24 \mathrm{hr}$ and by about $10 \%$ at $48 \mathrm{hr}$ for specimens in thick-walled, steel cylinders [inner diameter $\left(d_{i}\right)$ 12-40 mm, outer diameter $\left(d_{o}\right)$ 102-172 mm, height $(h) 100 \mathrm{~mm}$ ]. They also reported increased expansive pressures proportional to the mix water temperature. In a similar study, (Hinze and Brown, 1994) also used metal cylinders $\left(d_{i}=25-50 \mathrm{~mm}\right.$, $d_{o}=57-72 \mathrm{~mm}, h=100 \mathrm{~mm}$ ). At ambient temperatures of $20-45^{\circ} \mathrm{C}$, the $24 \mathrm{hr}$ expansive pressure generated at $20^{\circ} \mathrm{C}$ was approximately half of that produced at $30^{\circ} \mathrm{C}$ and onequarter of that generated at $45^{\circ} \mathrm{C}$. More recently, Laefer et al. (2010) conducted an investigation on 33 concrete blocks, each $0.77 \mathrm{~m}^{3}$ and found that the time to first crack (TFC) decreased by $13 \mathrm{hr}$ when the ambient temperature was increased from $24^{\circ} \mathrm{C}$ to $38^{\circ} \mathrm{C}$, while minimum demolition time (MDT) was reduced by about $4 \mathrm{hr}$. Similarly, a $22.8^{\circ} \mathrm{C}$ increase in the mix water temperature (from the $15^{\circ} \mathrm{C}$ as instructed by manufacturer to $37.8^{\circ} \mathrm{C}$ ) reduced the TFC and MDT by about $6 \mathrm{hr}$ and $3 \mathrm{hr}$, respectively, for $0.77 \mathrm{~m}^{3}$ samples of $42.9 \mathrm{MPa}$ compressive strength.

Cold temperatures would seem to have the reverse effect. A single field experiment on a reinforced concrete pier at $13^{\circ} \mathrm{C}$ required $96 \mathrm{hr}$ for sufficient post-chemical cracking for removal (Dowding and Labuz, 1982). Natanzi et al. (2016a) investigated heat and expansive pressure developed through the hydration process under cool and moderate ambient temperatures $\left(2-19^{\circ} \mathrm{C}\right)$ in thin-walled, steel cylinders. In that study, the pressure varied by $20 \mathrm{MPa}$ over the $17^{\circ} \mathrm{C}$. They also reported hydration heats of as much as triple the ambient temperature and volumetric expansion 1.1-1.4 times that of the 
SCDA's original material volume. While these studies clearly indicate certain performance trends, the outcomes cannot be directly correlated to industrial usage, and to date, there has been no study of SCDA performance in large-scale concrete samples at temperatures below $20^{\circ} \mathrm{C}$. Given that most industrial environments are in that temperature range, such information should be highly beneficial to the economical and efficient application of SCDAs in the field. As such, this is the topic of this paper.

\section{Experimental investigation}

\subsection{Sample and experimental conditions}

The study presented herein investigated six large-scale, unreinforced concrete blocks involving two different material strengths and two distinct ambient temperatures. Batch A included 3 blocks (each $1 \mathrm{~m}^{3}$ ) and Batch B 3 blocks (each $0.77 \mathrm{~m}^{3}$ ). Instead of drilling into the material to insert the SCDA slurry, each block had a vertical hole cast into its centre to avoid micro-cracking prior to the SCDA's introduction (Fig.1). In this study, a single hole and the ratio $k \sim 12$ was selected, with $L=(457.2 \mathrm{~mm}$ and $500 \mathrm{~mm})$ from the centre to the boundaries. A hole diameter of $40 \mathrm{~mm}$ was employed and located at a depth of $70 \%$ of the block. Block size and geometry were chosen to minimize scaling and boundary condition problems; the samples can be considered as representative of individual footings or boulders (Laefer et al., 2010). Batch A (compressive strength of $33.1 \mathrm{MPa}$ ) was tested at an average temperature of $19.0^{\circ} \mathrm{C}$, while Batch $\mathrm{B}(16.8 \mathrm{MPa})$ was tested at a mean temperature of $16.4^{\circ} \mathrm{C}$.

Experiments were conducted with a commercially available SCDA (Dexpan ${ }^{\mathrm{TM}}$ Type II, Table 1). The manufacturer's instructions were followed with respect to the water/chemical ratio $(30 \%)$, mixing water temperature $\left(15^{\circ} \mathrm{C}\right)$, and time to pour the 
SCDA slurry into the boreholes after mixing with water (10-15 minutes) (Dexpan, 2016). The concrete was comprised of sand, cement, and water (Table 2) to avoid heterogeneity within the specimens.

\subsection{Data measurement}

To monitor cracking and displacement, visual grids were overlaid all surfaces $100 \mathrm{~mm}$ (Batch A) and $102 \mathrm{~mm}$ (Batch B) [Figs.1-2]. Crack widths were recorded with $25.4 \mathrm{~mm}$ dial gauges (with mechanical rulers for redundancy) at 4 levels along each specimen's height (Fig.1). Vernier callipers readings were taken along the crack lengths, at the intersection of the gridlines and the crack lines across each specimen (Fig.2). Crack lengths were also marked on each block during testing to record their temporal progression. Temperatures were recorded every 15-30 min., with 4 thermocouple cables cast into each concrete block, 2 cast within the SCDA, and 1 left on top of each block.

\subsection{Retesting}

At the end of testing, two of the six blocks remained incompletely cracked. This raised the question of whether reapplication of SCDA would induce further cracking. To test this, the original, solidified SCDA was vacuumed out and new SCDA slurry was introduced. A tube slightly smaller than the diameter of the hole in the original test was wrapped with a $\sim 1 \mathrm{~mm}$ thick plastic, inserted into the hole of each of the two incompletely, cracked blocks. The tube was then withdrawn, leaving the plastic as a lining for the hole to prevent SCDA leakage through the original cracks. This procedure ensured that the SCDA quantity was consistent with the original test. SCDA slurry was reintroduced using the original procedure. Cracks, displacements, and temperatures were similarly recorded over the subsequent days. 
One of the main challenges in benchmarking SCDA products is the absence of a wellestablished set of quantifiable parameters with which to discuss performance. Laefer et al. (2010) proposed three criteria to determine the demolition potential of SCDAs:

1. Time to First Crack (TFC) - the time after introduction of an SCDA when the first easily detectible crack appears in the surrounding material (as opposed to within the SCDA itself).

2. Cumulative crack width is the maximum summation of the widths of all cracks around the perimeter of the block of material to be removed.

3. Minimum Demolition Time (MDT) - time for the cumulative crack width around the perimeter of the sample to reach at least $25.4 \mathrm{~mm}$ (to facilitate mechanical extraction of the cracked material of an industrial sized material of $0.77-1.00 \mathrm{~m}^{3}$ ). Although this may be the most significant parameter for demolition, the numeric value on which to base the MDT may vary depending on specific circumstances (e.g. site conditions, access, and material needing demolition); work has yet to be done to test the viability of a single MDT value for multiple materials and various geometries.

The objective of this research was to determine correlations between time and demolition parameters in unreinforced concrete (or soft rock) when using a commercial SCDA in cool environments and to begin establishing parameters that could be incorporated into a lab-scale standard for future benchmarking. The current experimental scale was intended to reflect fieldwork. For that, crack formation and propagation were compared for different material strengths and ambient temperatures. Additionally, temperature changes within the SCDA slurry were considered. 


\section{Experimental results and discussion}

Results including ambient temperature, TFC, and MDT for each block are presented in Table 3. Crack propagation rates (width and length) were also investigated.

\subsection{Crack width versus time}

Despite the manufacturer's guidelines predicting cracking within $0.75-1.00 \mathrm{hr}$ after SCDA introduction, all 6 blocks $\left(0.77-1.00 \mathrm{~m}^{3}, 16.8-33.1 \mathrm{MPa}\right)$ tested at $16.1-19.3^{\circ} \mathrm{C}$ required at least $24 \mathrm{hr}$ before any visible surface cracking occurred. Batch A $\left(1.00 \mathrm{~m}^{3}\right.$, strength $33.1 \mathrm{MPa}$ ) required more than $25 \mathrm{hr}$ to reach TFC (Table 3). Cracking continued for 5 days for Blocks 1 and 2 and nearly 8 days for Block 3, something heretofore not reported in the literature. Notably, in Batch B TFC occurred about $3.5 \mathrm{hr}$ later (at $29 \mathrm{hr}$ ), even though the specimens were smaller (only $0.77 \mathrm{~m}^{3} \mathrm{vs} 1.00 \mathrm{~m}^{3}$ ) and weaker (only 16.8 MPa vs 33.1 MPa). This can be explained by the lower ambient temperature in Batch B (see Section Influence of temperature). Conversely, MDT took more time in the larger, stronger Batch A blocks (Table 3). MDT was largely proportional to material strength. Batch B blocks were only about half as strong as Batch A and had an average MDT of approximately $60 \%$ of Batch A's (Table 3). So, MDT appeared to correlate with the material strength (irrespective of ambient temperature or specimen size), while TFC was more influenced by ambient temperature $\left(25.5 \mathrm{hr}\right.$ at $19^{\circ} \mathrm{C}$ and $29.0 \mathrm{hr}$ at $16.4^{\circ} \mathrm{C}$ ). MDT was reached within $24 \mathrm{hr}$ after TFC in Batch B but required nearly $48 \mathrm{hr}$ for Batch A (40.7-49.4 hr, Table 4).

Figures 3 and 4 show cumulative crack widths measured by vernier callipers across the top face of the block and at three levels on the sides (high, middle, and low). In Blocks 1-3 (Batch A), cracking spread quickly after initiation and opened quite uniformly 
throughout the block height. In contrast, in Blocks 4-6 (Batch B) cracks widened more in the upper regions, and never developed in the lower portions to the same extent (see Fig. 3 vs Fig. 4).

At $36 \mathrm{hr}$ after SCDA introduction, cumulative crack width on the perimeter of Blocks 4 and 5 was approximately $16 \%$ of the hole diameter $(D=40 \mathrm{~mm})$, and about $9 \%$ in Block 6 (Table 5). However, after 48 hr, cumulative crack width was approximately equal to the hole diameter in Blocks 4 and 5 and about 74\% of that in Block 6 (Table 5). The Batch A blocks (1-3) only achieved cumulative crack widths $15-39 \%$ of the hole diameter at $60 \mathrm{hr}$ (Table 5), at which time all Batch B blocks had extended to $125 \%$ of the hole diameter. At the end of demolition (85-186 hr), cumulative crack width on the top face of the 6 blocks was similar, av. 161\% of the hole's diameter (Table 5). So irrespective of ambient temperature, concrete strength, sample size and cracking characteristics, cumulative maximum crack widths $\left(w_{c m a x}\right)$ were ultimately nearly indistinguishable. The single maximum crack width at the end of testing $\left(w_{\text {smax }}\right)$ was less consistent between blocks, and those of Batch B were only $73 \%$ of those of Batch A $(83.8 \%$ vs $114.4 \%)$.

Cracks on the top face were either Y-shaped or bisected. A typical major crack (largest crack branch) shown for Block 3 is plotted in Fig.5, along with the maximum cumulative crack width. Block 3 cracks are shown in Fig.2, with their widths displayed in Fig.6. In Blocks 1-4, there were three major cracks (Y-shaped) across the specimen tops but only two major cracks (bisected) emerged in Blocks 5 and 6. This observation is similar to a previous study (Laefer et al., 2010), where 33 concrete blocks were tested 
under warmer temperatures (average $22^{\circ} \mathrm{C}$ ) with a different SCDA. In that study, no definitive reason was ascertained as to crack patterning.

In Fig.7, at MDT, the average maximum single crack width in Batch B was $\sim 60 \%$ of the cumulative crack width at the samples' perimeters. In the stronger Batch A blocks, tested at the higher ambient temperature $\left(19^{\circ} \mathrm{C}\right.$ vs $\left.16.4^{\circ} \mathrm{C}\right)$, this ratio was $80-90 \%$. Cumulative crack width distribution in the lower strength Batch B blocks was more uniform than that in the higher strength concrete blocks of Batch A. These phenomena can be explained based on energy dissipation. Batch A was approximately twice as strong as Batch B (Table 2) so more energy was needed to create the initial crack in each Batch A block. After the initial crack occurred, it was easier for a crack in Batch A to widen rather than to create a new crack. Consequently, the maximum single crack width in Batch A dominated the cumulative crack width measurement. Inversely, in the weaker Batch B blocks' energy generated by SCDA could break a new crack $\left(3^{\text {rd }}\right.$ branch), as well as expand existing ones.

\subsection{Crack propagation}

Here, specific characteristics of crack propagation are discussed, as represented by crack length on the unfolded planes (Fig.2). Initially, micro-cracks occurred around the holes. Some subsequently extended to the specimens' perimeters and down their height. These were considered major cracks. Those that did not progress were labeled as minor cracks. In Blocks 2 and 4, all cracks became major ones. The other blocks developed both major and minor cracks. 
Since minor cracks are insufficiently large for demolition, it is necessary to evaluate when a minor crack becomes a major one. To assist in this, the maximum length of the minor cracks on the top face will be designated as $l_{m}$. A crack is only major, if it propagates further than $l_{m}$ (i.e. out of the dashed circle in Fig. 2). Herein, the time at which a crack extends beyond $l_{m}$ is termed Time to First Major Crack (TFMC). The original distance between the hole edge to the periphery was approximately $437 \mathrm{~mm}$ for Batch B and $480 \mathrm{~mm}$ for Batch A and to the specimen bottom was 1,352 $\mathrm{mm}$ for Batch B and 1,480 mm for Batch A. Table 6 shows the weaker Batch B blocks tested under colder temperatures achieved a major crack at $l_{m}>7 D$, while the larger, stronger Batch A blocks tested under warmer conditions required a significantly greater distance $l_{m}>$ 12D. For Batch B, average TFMC (29.4 hr) was $\sim 0.4 \mathrm{hr}$ after TFC (29.0 hr) and ranged between $25.5 \mathrm{hr}$ and $46.4 \mathrm{hr}$ in Batch A (Table 3). In other words, TFMC occurred after TFC by $13.8 \mathrm{hr}$ and $20.8 \mathrm{hr}$ in Blocks 3 and 1, respectively.

The single largest crack width in each block is illustrated as a percentage of the MDT (Fig.7), and progression over time is shown in Fig.8. For Batch B blocks, once cracking began, cracks rapidly reached the top face peripheries - about $1 \mathrm{hr}$ (approximately $30 \mathrm{hr}$ after SCDA introduction) for Blocks 4 and 5 and $2.8 \mathrm{hr}(31.8 \mathrm{hr}$ after SCDA introduction) for Block 6. However, the larger, stronger Batch A blocks required nearly 2 days for initial cracking to reach the block edges (Table 3). Times for cumulative cracks to propagate from the hole to the bottom of the sample were distinctive. Blocks 4 and 5 needed only $3.5 \mathrm{hr}$ to crack completely through, once cracking began, while Block 6 needed $8 \mathrm{hr}$ (Table 3). In contrast, Batch A blocks took 47.5-75.1 hr after SCDA introduction for cracks to reach the bottom. Once cracking began, it took $\sim 22-$ $24 \mathrm{hr}$ for cracks in Blocks 1 and 3 to reach the bottom, and nearly $50 \mathrm{hr}$ in Block 2. No 
specific reason was apparent for the differences in the two batches or amongst individual blocks.

\subsection{Crack width opening rates}

Two distinct cracking stages were identified during demolition. When cumulative crack widths were less than $25.4 \mathrm{~mm}$, opening rates progressed rapidly and linearly with time (Stage 1). Beyond this, cumulative crack widths opened less rapidly and less linearly (Stage 2) [Figs. 3-5]. These velocities were designated as $v_{w 1}$ and $v_{w 2}$, respectively. Since cumulative crack widths in Stage 1 were linear with time, $v_{w 1}$ was computed by dividing crack width by time. After reaching MDT, the relationship looked non-linear but crack opening occurred over very small time increments so an average $v_{w 2}$ was obtained by integrating across each short time step.

Fig.9 shows $v_{w l}$ was $1.45-2.33 \mathrm{~mm} / \mathrm{hr}$ in Batch B but only $0.51-0.62 \mathrm{~mm} / \mathrm{hr}$ in Batch A. Stage 2 velocities for all blocks were generally slower $\left(v_{w 2}\right.$ ranged $0.73-0.96 \mathrm{~mm} / \mathrm{hr}$ in Batch B and 0.35-0.73 mm/hr in Batch A). In Batch A, opening velocities in the two stages did not differ greatly, unlike those in Batch B where they were highly distinctive. In Batch B, the ratio of crack opening velocity $v_{w 2} / v_{w 1}$ was 0.32 and 0.39 for Blocks 4 and 5, whilst 0.66 for Block 6 (Table 4). In Batch A the ratios were 1.13 and 1.28 for Blocks 1 and 2, and 0.68 for Block 3. No correlations were apparent for the velocity ratios with ambient temperature, block size, or strength. The final maximum cumulative crack widths $w_{\max }$ were similar for all blocks $(62-66 \mathrm{~mm})$, despite significant differences in cracking velocities and overall times (Table 4). 
Crack widths varied from a hole's edge to the bottom of its block. The widths in some major branches were smaller around the hole and wider at the peripheries (Fig.10a). Inversely, some branches were largest at the hole and decreased gradually to the blocks' peripheries (Fig.10b). When the critical tensile strength of concrete was overcome, cracks formed around the hole and widened. The former case can be explained by thermal stress theory in a thick cylinder (Timoshenko and Goodier, 1970). During SCDA hydration, a large amount of heat was generated surrounding the hole. Material temperature disparities between the hole's circumference and the block's edges cause tensile stresses close to the edges and compressive stresses near the hole (Timoshenko and Goodier, 1970). Also, there was some sliding between crack surfaces and rotation of pieces around the block's center, thereby, making crack widths on block edges wider at selective locations.

\subsection{Influence of temperature}

Temperature has been influential in similar studies (Hinze and Brown, 1994, Laefer et al., 2010), but the relative impacts of temperature of the SCDA, the material to be demolished, and the surrounding air has not been considered. Throughout testing, the ambient, SCDA, and concrete temperatures remained distinctive (see Fig.11 for typical readings). Ambient temperature at Blocks 3 and 6 were on average $0.5^{\circ} \mathrm{C}$ colder than others in their batch (Table 3) due to their position in the lab. Small differences in ambient temperature did not strongly influence the TFC, but did delay MDT by nearly 5 $\mathrm{hr}$ in Batch A and more than $6 \mathrm{hr}$ in the smaller and weaker Batch B samples (Table 3). The two effects on final crack widths are shown in Fig.3 versus Fig.4. 
Additionally, when the ambient temperature was reduced by as little as $0.5^{\circ} \mathrm{C}$, the initial crack width velocity $v_{w l}$ decreased an average of $14 \%$ in Batch A (strength $33.1 \mathrm{MPa}$ ) and $37 \%$ in Batch B (material strength $16.8 \mathrm{MPa}$ ). In the high strength material (Batch A), Block 3's $v_{w 1}$ was $0.085 \mathrm{~mm} / \mathrm{hr}$ slower than Blocks 1 and $2(0.51 \mathrm{~mm} / \mathrm{hr})$ versus an average of $0.60 \mathrm{~mm} / \mathrm{hr}$, respectively (Table 4). For Batch B, the decrease of $0.5^{\circ} \mathrm{C}$ in the ambient temperature resulted in a significant decrease $0.85 \mathrm{~mm} / \mathrm{hr} v_{w l}$ compared to Blocks 4 and $5(1.45 \mathrm{~mm} / \mathrm{hr}$ vs an average of $2.3 \mathrm{~mm} / \mathrm{hr})$. Notably, as the maximum crack widths at the end of the testing were largely indistinguishable (Table 4), the overall, final, crack width rates can be considered equivalent, once cracking initiated.

Ambient temperature also impacted crack length growth velocities. Although Batch A blocks were warmer, their cracks required at least twice as long to reach the specimen bottom than the Batch B blocks (Fig.8). The overall elongation velocities $\left(v_{e-a l l}\right)$ for Batch A were 29.8-67.6 mm/hr but 169.0-386.3 mm/hr for Batch B, with significant speed differences from the hole to the periphery $\left(v_{e-p}\right)$ and then from the periphery to the block bottom $\left(v_{e-b}\right)$ [Table 4]. This warrants further investigation with respect to variations in ambient temperature and material strength.

\subsection{SCDA re-application}

Two SCDA temperature peaks occurred (Fig.11; Table 7). The first peak in Batch A blocks was within 13-16.5 hr, while it took 18-22 hr in the colder Batch B environment. Conversely, in Batch B, the second peak appeared after nearly 2 days (42-47 hr), while those in Batch A required additional time (57-66 hr). In both batches, the first peak occurred before TFC and is likely to be the hydration point. In the warmer Batch A conditions $\left(19^{\circ} \mathrm{C}\right)$, the second peak occurred before MDT (57-66 hr vs $\left.70.4 \mathrm{hr}\right)$ but 
generally after MDT (42-47 hr compared to $42.2 \mathrm{hr}$ ) for Batch B. In all cases, the SCDA temperature remained very low $\left(17.4-19.4^{\circ} \mathrm{C}\right)$. Heat generated by the SCDA was probably diffused by the surrounding concrete, so the "gun phenomenon" (Soeda et al., 1994) did not happen.

The probable heat transfer was further confirmed when SCDA was re-introduced into Blocks 1 and 3 to see if further cracking could be induced. In that case, the original holes were lined with a double plastic layer $\sim 1 \mathrm{~mm}$. Peak temperatures now rose to $80^{\circ} \mathrm{C}$ (Fig. 12), probably due to the insulating effect of the plastic. The potentially greater pressure developed under these higher SCDA temperatures were released through the existing cracks so no direct comparisons can be made. Although there may have been some impact of the possibly higher water content, because of the absence of absorption opportunities through the concrete, prior testing would indicate that any change caused by water content loss would increase the hydration temperature (Hinze and Brown, 1994, Hinze and Nelson, 1996) which was the opposite of what was seen.

During the re-testing of Blocks 1 and 3, the average ambient temperature was slightly higher than in the initial test $\left(20.8^{\circ} \mathrm{C}\right.$ vs $\left.19.0^{\circ} \mathrm{C}\right)$. Notably, no new cracks formed during the re-testing. Instead, the existing major cracks from the initial test continued to open, as was predicted. At approximately $36 \mathrm{hr}$ after SCDA reapplication, cumulative crack widths in both blocks opened 4-10 mm more than those recorded at the end of initial testing (Table 8 and Fig.13). After reapplication, the maximum cumulative crack width on the top face opened significantly $(+10 \mathrm{~mm})$, while individual cracks opened only another $+1-2 \mathrm{~mm}$ each after $36 \mathrm{hr}$, except for each block's single, widest crack, which opened approximately $+10.5 \mathrm{~mm}($ Block 3$)$ and $+7 \mathrm{~mm}$ (Block 1$)$. This proves the value 
of SCDA reapplication for rectifying incomplete demolitions. Overall, once the cracking began again ( 2 hours after SCDA reapplication), there was significant widening within the first few hours ( $4 \mathrm{hr}$ for Block 1 and $3 \mathrm{hr}$ for Block 3 ). The velocity after reapplication $\left(v_{r l}\right)$ in Block 1 was $1.6 \mathrm{~mm} / \mathrm{hr}$, and $2.48 \mathrm{~mm} / \mathrm{hr}$ for Block 3 (at least twice as fast as any of the initial crack widening velocities). After approximately $4 \mathrm{hr}$ of cracking, the additional cumulative crack width opening rate $\left(v_{r 2}\right)$ was notably slower $\sim 0.03 \mathrm{~mm} / \mathrm{hr}$ in Block 1 and $0.04 \mathrm{~mm} / \mathrm{hr}$ in Block 3 (Fig. 13). Subsequent to this point, crack widths are likely to have reduced confinement beyond the expansion capacity of the SCDA.

\subsection{Discussion}

In the present study, cracks were not observed until at least $25.5 \mathrm{hr}$ after SCDA introduction, an order of magnitude longer than the $0.75-1.00 \mathrm{hr}$ predicted by the manufacturers (Dexpan, 2016). Additionally, samples continued to crack for several days, albeit at a slower rate - something not previously reported. Manufacturers' data appear to have been collected under vastly different conditions than the testing herein, but as no specifics were available as to sample size, sample strength, and ambient temperature, further comparison is not possible.

The experiments herein showed that while TFC was influenced strongly by ambient temperature, the arguably more critical MDT was more controlled by material strength, with stronger materials requiring more time. This is consistent with prior large-scale tests (Laefer et al., 2010) at higher ambient temperatures using a different SCDA (Fig.14), although the Dexpan seems more temperature sensitive than the Bristar. Further refinement based on ambient temperature, is likely as a half a degree reduction 
extended the MDT by $6.5 \mathrm{hr}$. Lower temperatures also retarded initial width development, although final values were not definitively impacted.

Material strength also inhibited cumulative crack width growth as a function of time. In the strong material (Batch A), cumulative crack width was $\sim 15-39 \%$ of the hole's diameter at $60 \mathrm{hr}$ of testing, but more than 100\% for the weaker (Batch B) blocks. At the end of demolition, the maximum crack width was approximately $161 \%$ of the borehole diameter in both Batches A and B. Additionally, maximum single crack width at the end of testing in the stronger material was $114 \%$ of the original hole diameter, while only $83.8 \%$ in the weaker one. In contrast, Dowding and Labuz (1982) reported a maximum crack width of only $\sim 40 \%$ of the $38 \mathrm{~mm}$ boreholes after $90 \mathrm{hr}$ in slabs $(0.2-$ $\left.1.0 \mathrm{~m}^{3}\right)$ of the much stronger dolomite $(165 \mathrm{MPa})$. At $90 \mathrm{hr}$, the maximum crack width in Batch A was only $90.4-115.3 \%$ of the borehole diameter, and cracking persisted for up to $186 \mathrm{hr}$.

Independent measuring of ambient temperature from that of the SCDA showed a profound tendency for heat transfer from the SCDA into the surrounding concrete. When the hole was lined with plastic, temperatures of nearly an order of magnitude higher were achieved. As no published studies to date have considered this phenomenon, the direct applicability is called into question of both manufacturers' and independent results, which discuss pressure as a function of ambient temperature (Dexpan, 2016, Dowding and Labuz, 1982, Hinze and Brown, 1994, Laefer et al., 2010).

Furthermore, SCDA temperature peaked twice during the testing. The first was within 13-22 $\mathrm{hr}$. The second appeared about $24 \mathrm{hr}$ later in the $16.8 \mathrm{MPa}$ concrete and $48 \mathrm{hr}$ in 
the 33.1 MPa concrete. Cracking always occurred prior to the second peak, but further extrapolation is not possible from the limited dataset. While obviously linked, the exact relationship between pressure development and hydration remains unknown.

\section{Conclusions and future work}

The current study examined six, relatively large-scale, concrete blocks under moderate ambient temperatures. Initial cracking required more than $25 \mathrm{hr}$ after SCDA introduction, and cracking continued for up to 8 days. The low SCDA temperatures achieved indicate significant thermal transfer from the SCDA to the concrete, which may reduce maximum pressures and discount available usage guidelines provided by SCDA manufacturers. Cool ambient temperatures vastly delayed the time to first crack and notably extended the cracking duration. Thus, pre-lining the holes for better SCDA heat retention is ripe for consideration. SCDA reapplication was effective hole widening and required an order of magnitude less time than the original procedure for cracking onset.

The relative influence of the competing factors of specimen size, strength, and ambient temperature is still not fully known, although several new terms are introduced to further enable performance comparisons between specimens and testing locales: crack widening velocities, an overall crack elongation velocity, minor versus major cracks, and time to first major crack. These will become the basis of reporting future experimental and numerical work.

Furthermore, while work to date has largely focused on in situ rock and concrete blocks, some highly preliminary work has just been published on a series of four, single-wythe, 
concrete masonry unit wallettes $(66.5 \mathrm{~cm} * 22.5 \mathrm{~cm})$ in a cement-based mortar [Natanzi et al. 2016b]. That work demonstrated the potential of cracking masonry walls by inserting SCDA through holes drilled through the mortar joints. The full feasibility of doing this, however, is far from established given (1) the largely uncontrolled cracking mechanism, (2) the fact that the mortar joints in the wallette were significantly larger than typically seen in the field, and (3) the single wythe nature of the wall. The efficacy of the procedure, however, has now been established and creates a clear pathway for more extensive work in the largely unexplored potential use of SCDAs. The approach may have its greatest impact in selective unit removal. 
Tables and Figures

List of Tables:

Table 1 Chemical specification

Table 2 Mix design for concrete blocks

Table 3 Synthetic data of testing results

Table 4 Velocities of cumulative crack width opening and crack length growth

Table 5 Relationship between crack widths and hole diameter

Table 6 Length of minor cracks

Table 7 SCDA hydration time

Table 8 Cumulative crack width at SCDA reapplication 


\section{List of Figures:}

Fig.1 Typical specimen configuration - Batch B Block 4.

Fig.2 Sketch of the final crack propagation - Block 3 (Typical of Batch A).

Fig.3 Cumulative crack width versus time - Block 1 (Typical of Batch A).

Fig.4 Cumulative crack width versus time - Block 4 (Typical of Batch B).

Fig.5 Crack widths versus time - Batch A Block 3.

Fig.6 Single crack width at all measured positions per block - Batch A Block 3 .

Fig.7 Comparison between maximum single crack width and cumulative crack width at MDT.

Fig.8 Crack length versus time.

Fig.9 Velocities of cumulative crack width opening at Stage 1 and Stage 2.

Fig.10a Distribution of cumulative crack width on sides - Type 1 - Batch A Block 1.

Fig.10b Distribution of cumulative crack width on sides - Type 2 - Batch A Block 1.

Fig.11 Variation of temperatures throughout the demolition process - Batch B Block 4.

Fig.12 SCDA temperature inside the hole - Re-testing through SCDA reapplication.

Fig.13 Cumulative crack width opening at the second pour with plastic cover inner the hole surface - Batch A Block 3.

Fig.14 Trend of MDT versus material strength [Data from (Bristar, 2016)]. 
Table 1: Chemical specification

\begin{tabular}{ll}
\hline \hline Characteristic & Description of DEXPAN ${ }^{\text {TM }}$ Type II \\
\hline \hline Recommended temperature range: ${ }^{\circ} \mathrm{C}$ & $10-25$ \\
\hline Recommended water content: litres & 1.5 \\
\hline Water content selected: litres & 1.5 \\
\hline Water temperature: ${ }^{\circ} \mathrm{C}$ & 15 \\
\hline Chemical components & Silicon dioxide $\left(\mathrm{SiO}_{2}-5.1 \%\right)$, \\
& aluminium oxide $\left(\mathrm{Al}_{2} \mathrm{O}_{3}-1.6 \%\right)$ \\
& Ferric oxide $\left(\mathrm{Fe}_{2} \mathrm{O}_{3}-2.5 \%\right)$, calcium \\
& oxide $(\mathrm{CaO}-89.6 \%)$ \\
\hline \hline
\end{tabular}

Table 2: Mix design for concrete blocks

\begin{tabular}{llllll}
\hline \hline Batch & $\begin{array}{l}\text { Target } \\
\text { concrete } \\
\text { mix }\end{array}$ & $\begin{array}{l}\text { Water/ } \\
\text { cement }\end{array}$ & $\begin{array}{l}\text { Sand/ } \\
\text { cement }\end{array}$ & $\begin{array}{l}\text { Plasticizer } \\
\text { Sika } \\
\text { plastiment } \\
\mathbf{1 8 6}\left(\mathbf{1} / \mathbf{m}^{\mathbf{3}}\right)\end{array}$ & $\begin{array}{l}\mathbf{2 8} \text { day } \\
\text { compressive } \\
\text { strength, } \\
\text { MPa }\end{array}$ \\
\hline \hline A (Blocks 1-3) & Medium & 0.3 & $5 / 1$ & 0.8 & 33.1 \\
\hline B (Blocks 4-6) & Low & 0.3 & $5 / 1$ & 0.8 & 16.8 \\
\hline \hline
\end{tabular}

Table 3: Synthetic data of testing results

\begin{tabular}{lccccccccc}
\hline \hline $\begin{array}{l}\text { Block } \\
\text { number }\end{array}$ & $\begin{array}{c}\mathbf{T} \\
\left({ }^{\circ} \mathbf{C}\right)\end{array}$ & $\begin{array}{c}\text { TFC } \\
(\mathbf{h r})\end{array}$ & $\begin{array}{c}\text { TFMC } \\
(\mathbf{h r})\end{array}$ & $\begin{array}{c}\text { Time to } \\
\text { specimen } \\
\text { perimeter } \\
\text { (hr) }\end{array}$ & $\begin{array}{c}\text { Time to } \\
\text { specimen } \\
\text { bottom } \\
(\mathbf{h r})\end{array}$ & $\begin{array}{c}\text { MDT } \\
\text { (hr) }\end{array}$ & $\begin{array}{c}\text { Crack } \\
\text { Shape }\end{array}$ & $\begin{array}{c}\Delta \mathbf{T}^{*} \\
\left({ }^{\circ} \mathbf{C}\right)\end{array}$ & $\begin{array}{c}\Delta \mathbf{M D T}^{*} \\
(\mathbf{h r})\end{array}$ \\
\hline \hline 1 & 19.3 & 25.6 & 46.4 & 46.5 & 47.5 & 66.3 & $\mathrm{Y}$ & -0.6 & 8.6 \\
\hline 2 & 19.0 & 25.5 & 25.5 & 52.3 & 75.1 & 70.0 & $\mathrm{Y}$ & -0.3 & 4.9 \\
\hline 3 & 18.7 & 25.5 & 39.3 & 40.7 & 49.2 & 74.9 & $\mathrm{Y}$ & & \\
\hline Mean & $\mathbf{1 9 . 0}$ & $\mathbf{2 5 . 5}$ & $\mathbf{3 7 . 1}$ & $\mathbf{4 6 . 5}$ & $\mathbf{5 7 . 3}$ & $\mathbf{7 0 . 4}$ & - & $\mathbf{- 0 . 5}$ & $\mathbf{6 . 8}$ \\
\hline 4 & 16.6 & 29.0 & 29.0 & 29.6 & 32.5 & 40.2 & $\mathrm{Y}$ & -0.5 & 6.3 \\
\hline 5 & 16.5 & 29.0 & 29.0 & 30.0 & 32.5 & 39.9 & $1 / 2$ & -0.5 & 6.6 \\
\hline 6 & 16.1 & 29.0 & 30.3 & 31.8 & 37.0 & 46.5 & $1 / 2$ & & $\mathbf{6 . 5}$ \\
\hline Mean & $\mathbf{1 6 . 4}$ & $\mathbf{2 9 . 0}$ & $\mathbf{2 9 . 4}$ & $\mathbf{3 0 . 5}$ & $\mathbf{3 4 . 0}$ & $\mathbf{4 2 . 2}$ & - & $\mathbf{- 0 . 5}$ & $\mathbf{6 . 5}$ \\
\hline \hline
\end{tabular}

* Block 3 minus Blocks 1 \& 2, and Block 6 minus Blocks 4 \& 5

Table 4: Velocities of cumulative crack width opening and crack length growth

\begin{tabular}{|c|c|c|c|c|c|c|}
\hline $\begin{array}{l}\text { Block } \\
\text { num. }\end{array}$ & $\begin{array}{l}\mathbf{t}_{\max } \\
(\mathrm{hr})\end{array}$ & $\begin{array}{l}\mathbf{W}_{\mathrm{cmax}} \\
(\mathrm{mm})\end{array}$ & $\begin{array}{c}\mathrm{W}_{\mathrm{cmax}}-25.4 \\
(\mathrm{~mm})\end{array}$ & $\begin{array}{c}\text { MDT-TFC } \\
\text { (hr) }\end{array}$ & $\begin{array}{c}\mathbf{t}_{\max }-M D T \\
\text { (hr) }\end{array}$ & $\begin{array}{c}\mathbf{V}_{\mathrm{w} 1} \\
(\mathrm{~mm} / \mathrm{hr})\end{array}$ \\
\hline $\bar{~} 1$ & 120.4 & 63.53 & 38.13 & 40.7 & 54.2 & 0.62 \\
\hline 2 & 124.0 & 64.82 & 39.42 & 44.5 & 54.0 & 0.57 \\
\hline 3 & 185.5 & 64.21 & 38.81 & 49.4 & 110.6 & 0.51 \\
\hline Mean & 143.3 & 64.19 & 38.79 & 44.8 & 72.9 & 0.57 \\
\hline 4 & 94.0 & 64.94 & 39.54 & 11.2 & 53.8 & 2.27 \\
\hline 5 & 85.0 & 66.05 & 40.65 & 10.9 & 45.1 & 2.33 \\
\hline 6 & 85.0 & 62.48 & 37.08 & 17.5 & 38.5 & 1.45 \\
\hline Mean & 88.0 & 64.49 & 39.09 & 13.2 & 45.8 & 2.02 \\
\hline $\begin{array}{l}\text { Block } \\
\text { num. }\end{array}$ & $\begin{array}{c}\mathrm{v}_{\mathrm{w} 2} \\
(\mathrm{~mm} / \mathrm{hr})\end{array}$ & $\overline{\mathbf{v}_{\mathrm{w} 2} / \mathbf{v}_{\mathrm{w} 1}}$ & $\begin{array}{c}\mathbf{v}_{\mathrm{e}-\mathrm{p}} \\
(\mathrm{mm} / \mathrm{hr})\end{array}$ & $\begin{array}{c}\mathrm{v}_{\mathrm{e}-\mathrm{b}} \\
(\mathrm{mm} / \mathrm{hr})\end{array}$ & $\begin{array}{c}\mathrm{V}_{\mathrm{e}-\mathrm{all}} \\
(\mathrm{mm} / \mathrm{hr})\end{array}$ & \\
\hline 1 & 0.70 & 1.13 & 23.0 & 1000.0 & 67.6 & \\
\hline 2 & 0.73 & 1.28 & 17.9 & 43.9 & 29.8 & \\
\hline 3 & 0.35 & 0.68 & 31.6 & 117.6 & 62.4 & \\
\hline Mean & 0.59 & 1.03 & 24.2 & 387.2 & 53.3 & \\
\hline 4 & 0.73 & 0.32 & 728.3 & 315.4 & 386.3 & \\
\hline 5 & 0.90 & 0.39 & 437.0 & 365.8 & 386.3 & \\
\hline 6 & 0.96 & 0.66 & 156.1 & 175.9 & 169.0 & \\
\hline Mean & 0.87 & 0.46 & 440.5 & 285.7 & 313.9 & \\
\hline
\end{tabular}


Table 5: Relationship between crack widths and hole diameter

\begin{tabular}{|c|c|c|c|c|c|c|c|c|c|c|c|c|}
\hline Block & $\begin{array}{l}\mathrm{W}_{36 \mathrm{hr}}{ }^{*} \\
(\mathrm{~mm})\end{array}$ & \%D & $\begin{array}{r}\mathbf{W}_{48 \mathrm{hr}} \\
(\mathrm{mm}) \\
\end{array}$ & $\%$ & $\begin{array}{l}\mathbf{W}_{60 \mathrm{hr}} \\
(\mathrm{mm}) \\
\end{array}$ & \%D & $\begin{array}{l}\mathbf{W}_{\mathrm{cmax}} \\
(\mathbf{m m}) \\
\end{array}$ & \%D & $\begin{array}{l}\mathbf{W}_{\text {SMDT }} \\
(\mathbf{m m}) \\
\end{array}$ & \%DD & $\begin{array}{l}\mathbf{W}_{\text {smax }} \\
(\mathbf{m m}) \\
\end{array}$ & $\%$ \\
\hline$\overline{1} 1$ & - & - & - & - & 15.63 & 39.0 & 63.53 & 158.8 & 23.31 & " 58.3 & 466.85 & 1017.1 \\
\hline 2 & - & - & - & - & 7.92 & 19.8 & 64.82 & 162.1 & 20.07 & 50.2 & 38.67 & 96.7 \\
\hline 3 & - & - & - & - & 5.90 & 14.7 & 64.21 & 160.5 & 23.24 & 58.1 & 51.77 & 129.4 \\
\hline Mean & - & - & - & - & 9.82 & 24.5 & 64.19 & 160.5 & 22.21 & 55.5 & 45.76 & 114.4 \\
\hline 4 & 6.55 & 16.3 & 42.93 & 107.3 & 55.91 & 139.8 & 64.94 & 162.4 & 14.71 & 36.8 & 26.99 & 67.5 \\
\hline 5 & 6.25 & 15.6 & 40.63 & 101.5 & 55.42 & 138.6 & 66.05 & 165.1 & 14.12 & 35.3 & 37.63 & 94.1 \\
\hline 6 & 3.66 & 9.2 & 29.69 & 74.2 & 50.14 & 125.4 & 62.48 & 156.2 & 16.47 & 41.2 & 35.88 & 89.7 \\
\hline Mean & 5.49 & 13.7 & 37.75 & 94.4 & 53.82 & 134.6 & 64.49 & 161.2 & 15.10 & 37.8 & 33.50 & 83.8 \\
\hline
\end{tabular}

Table 6: Length of minor cracks

\begin{tabular}{lccc}
\hline \hline $\begin{array}{l}\text { Block } \\
\text { number }\end{array}$ & $\begin{array}{c}\mathbf{l}_{\mathbf{m}} \\
\mathbf{m m}\end{array}$ & $\begin{array}{c}\mathbf{D} \\
\mathbf{m m}\end{array}$ & $\mathbf{n}=\mathbf{l}_{\mathbf{m}} / \mathbf{D}$ \\
\hline \hline 1 & 460 & 40 & 11.5 \\
\hline 2 & $\mathrm{~N} / \mathrm{A}$ & 40 & $\mathrm{~N} / \mathrm{A}$ \\
\hline 3 & 475 & 40 & 11.9 \\
\hline 4 & $\mathrm{~N} / \mathrm{A}$ & 40 & $\mathrm{~N} / \mathrm{A}$ \\
\hline 5 & 304.8 & 40 & 7.1 \\
\hline 6 & 304.8 & 40 & 7.1 \\
\hline \hline
\end{tabular}

Table 7: SCDA hydration time

\begin{tabular}{lcccccc}
\hline \hline Block & \multicolumn{2}{c}{ Peak 1 } & \multicolumn{2}{c}{ Peak 2 } & \multicolumn{2}{c}{ Peak 2 - Peak 1 } \\
\cline { 2 - 7 } & $\begin{array}{c}\text { Time } \\
(\mathbf{h r})\end{array}$ & $\begin{array}{c}\mathbf{T} \\
\left({ }^{\circ} \mathbf{C}\right)\end{array}$ & $\begin{array}{c}\text { Time } \\
(\mathbf{h r})\end{array}$ & $\begin{array}{c}\mathbf{T} \\
\left({ }^{\circ} \mathbf{C}\right)\end{array}$ & $\begin{array}{c}\Delta \text { Time } \\
(\mathbf{h r})\end{array}$ & $\begin{array}{c}\Delta \mathbf{T} \\
\left({ }^{\circ} \mathbf{C}\right)\end{array}$ \\
\hline \hline 1 & 13.0 & 19.4 & 57.5 & 19.4 & 44.5 & 0.0 \\
\hline 2 & 13.0 & 19.4 & 57.0 & 19.4 & 44.0 & 0.0 \\
\hline 3 & 16.5 & 19.0 & 66.0 & 19.0 & 49.5 & 0.0 \\
\hline 4 & 22.0 & 18.2 & 43.0 & 18.6 & 21.0 & 0.4 \\
\hline 5 & 18.0 & 17.7 & 42.0 & 18.1 & 24.0 & 0.4 \\
\hline 6 & 18.0 & 17.4 & 47.0 & 17.5 & 29.0 & 0.1 \\
\hline \hline
\end{tabular}

Table 8: Cumulative crack width at SCDA reapplication

\begin{tabular}{cllcccc}
\hline \hline Block & Position & $\mathbf{W}_{\mathbf{0 h r}}$ & $\mathbf{W}_{\mathbf{1 2 . 5 h r}}$ & $\mathbf{W}_{\mathbf{1 3 . 1 7 h r}}$ & $\mathbf{W}_{\mathbf{3 6 . 1 7 h r}}$ & $\mathbf{W}_{\mathbf{3 6 . 5 h r}}$ \\
\hline \hline \multirow{3}{*}{1} & Top & 49.10 & 57.52 & - & - & 58.11 \\
\cline { 2 - 7 } & High & 58.33 & 61.50 & - & - & 62.00 \\
\cline { 2 - 7 } & Middle & 56.54 & 59.00 & - & - & 61.00 \\
\cline { 2 - 7 } & Low & 58.11 & 60.10 & - & - & 62.68 \\
\cline { 2 - 7 } & S-max* & 47.00 & 49.00 & - & - & 49.00 \\
\hline \multirow{5}{*}{3} & S-min* & 12.39 & 13.52 & - & - & 14.11 \\
\hline & Top & 53.39 & - & 62.25 & 63.44 & - \\
\cline { 2 - 7 } & High & 50.00 & - & 60.00 & 60.50 & - \\
\cline { 2 - 7 } & Middle & 46.59 & - & 58.20 & 60.34 & - \\
\cline { 2 - 7 } & Low & 45.00 & - & 52.00 & 52.50 & - \\
\cline { 2 - 7 } & S-max* & 50.00 & - & 60.00 & 60.50 & - \\
\cline { 2 - 7 } & S-min* & 5.82 & - & 6.44 & 6.72 & - \\
\hline \hline
\end{tabular}

* S-max: Maximum single crack width; S-min: Minimum single crack width.

Unit of data (crack width) is mm.

- : not measured items 


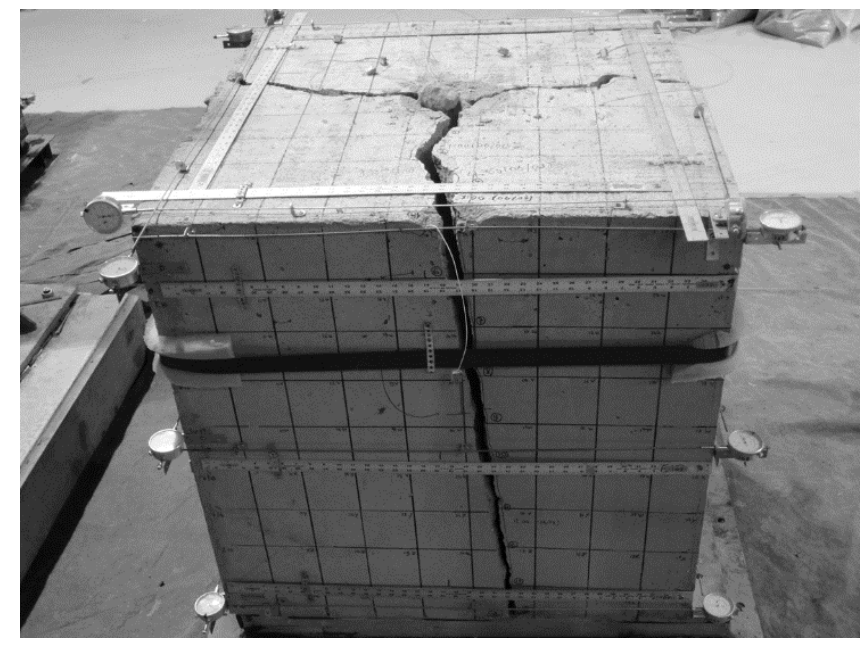

Fig.1 Typical specimen configuration - Batch B Block 4.

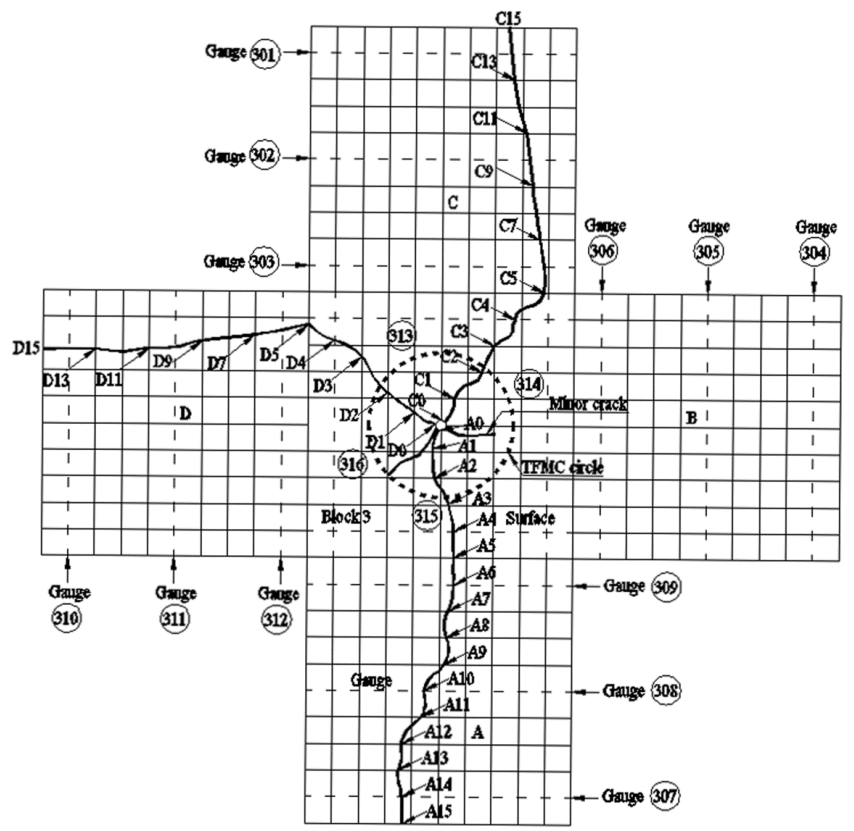

Fig.2 Sketch of the final crack propagation - Block 1 (Typical of Batch A).

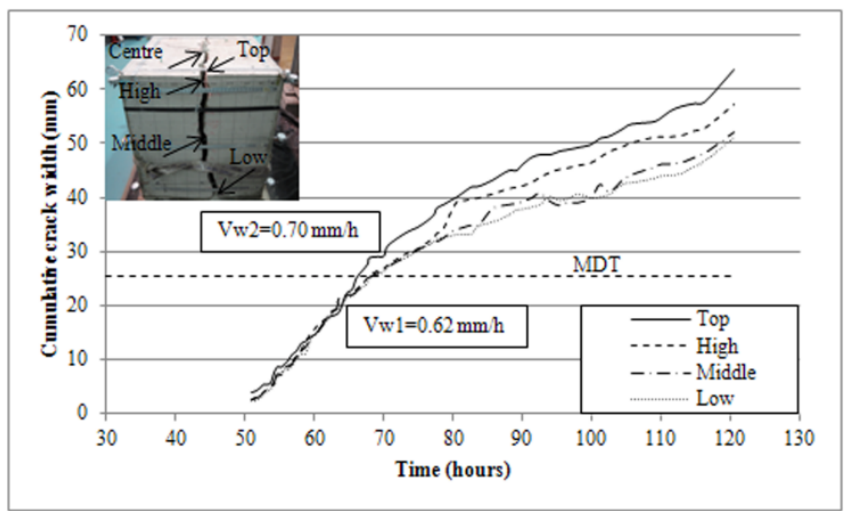

Fig.3 Cumulative crack width versus time - Block 1 (Typical of Batch A) 


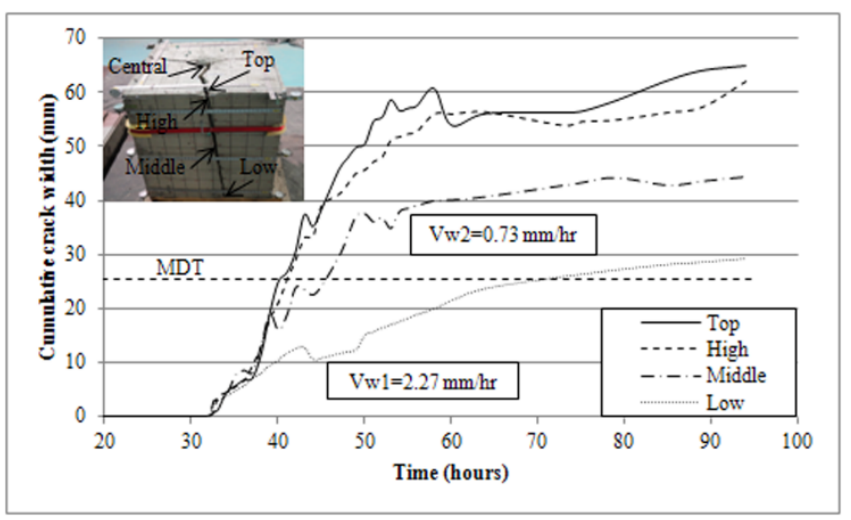

Fig.4 Cumulative crack width versus time - Block 4 (Typical of Batch B)

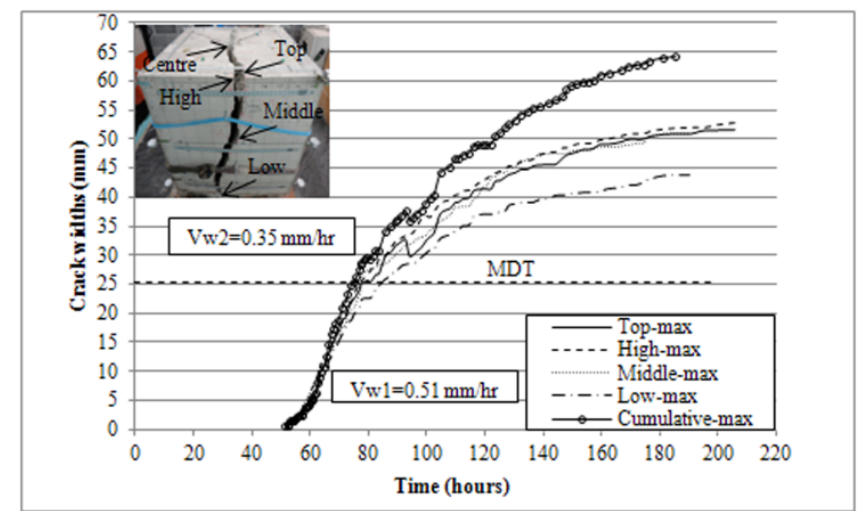

Fig.5 Crack width versus time - Batch A Block 3 


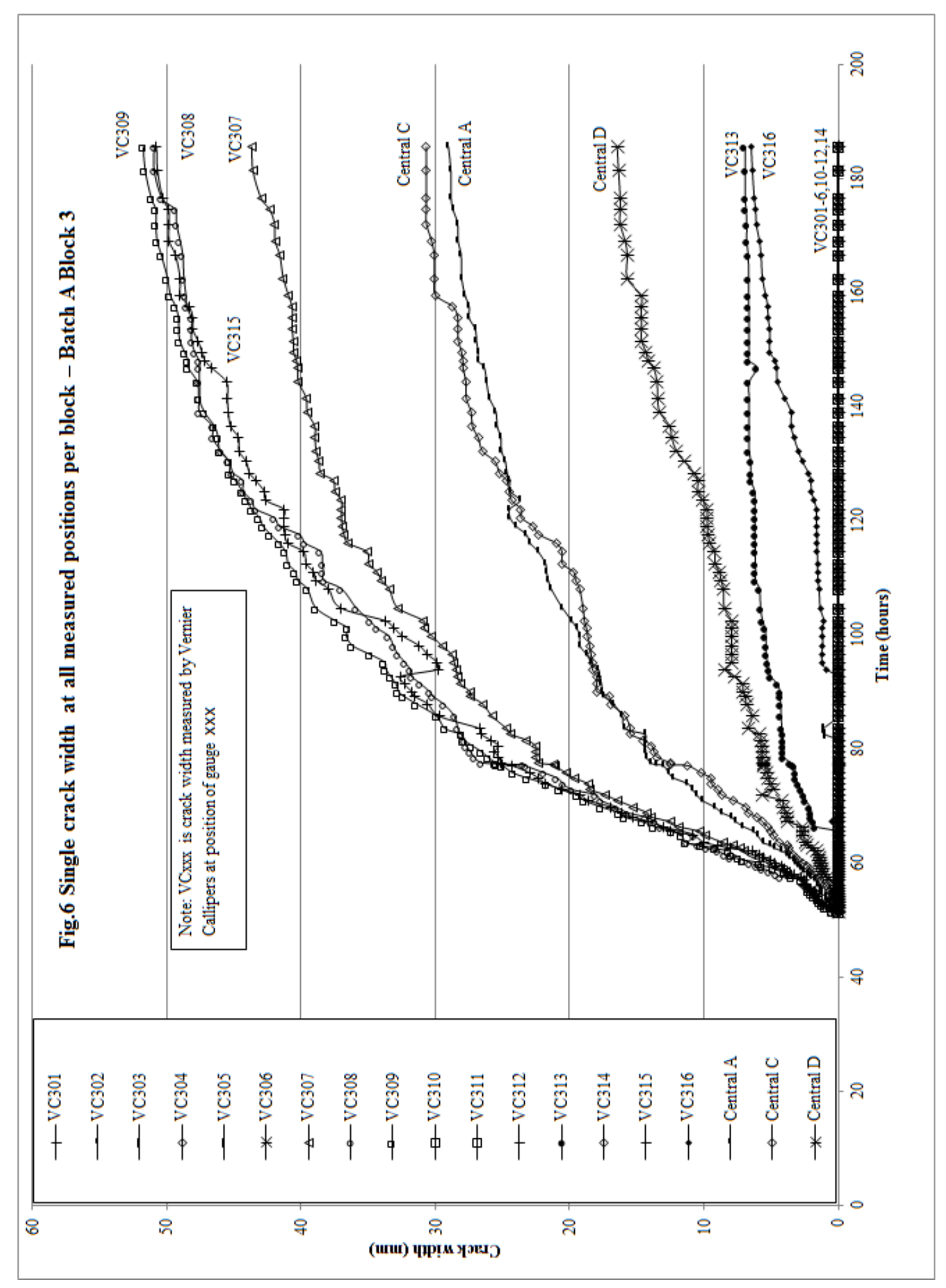




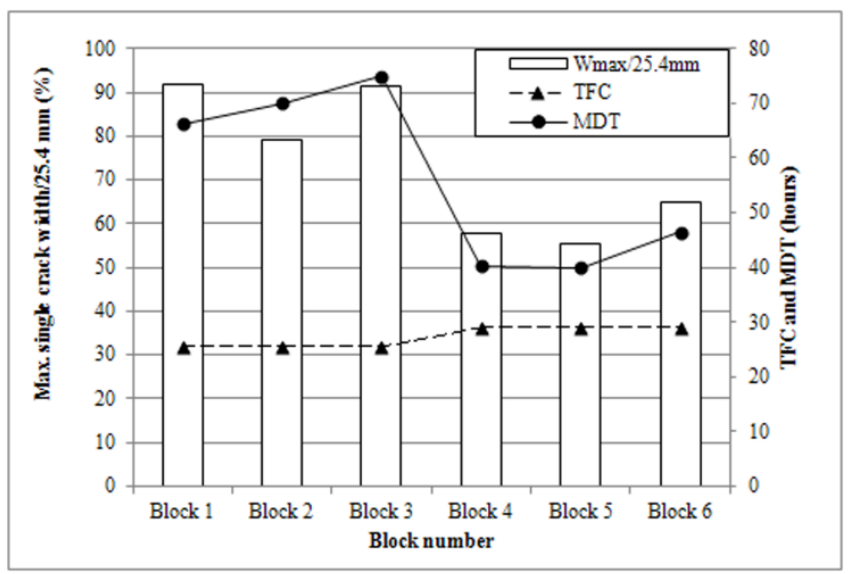

Fig.7 Comparison between maximum single crack width and cumulative crack width at MDT

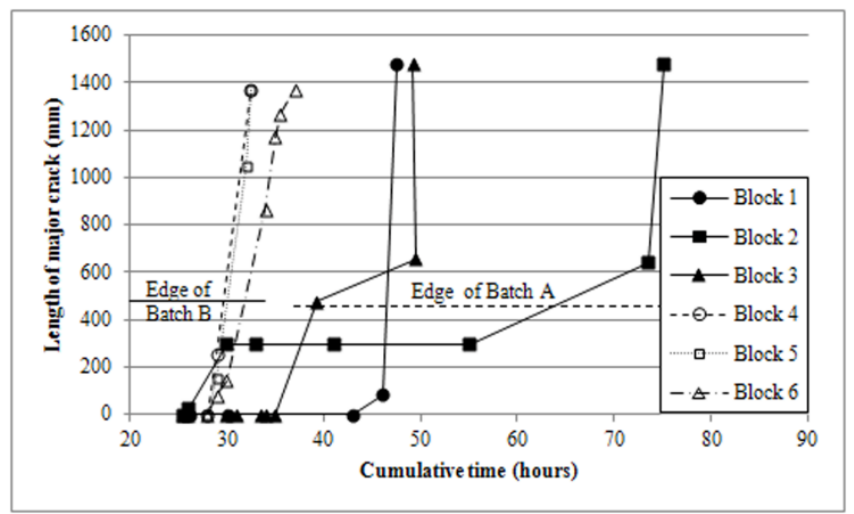

Fig.8 Crack length versus time

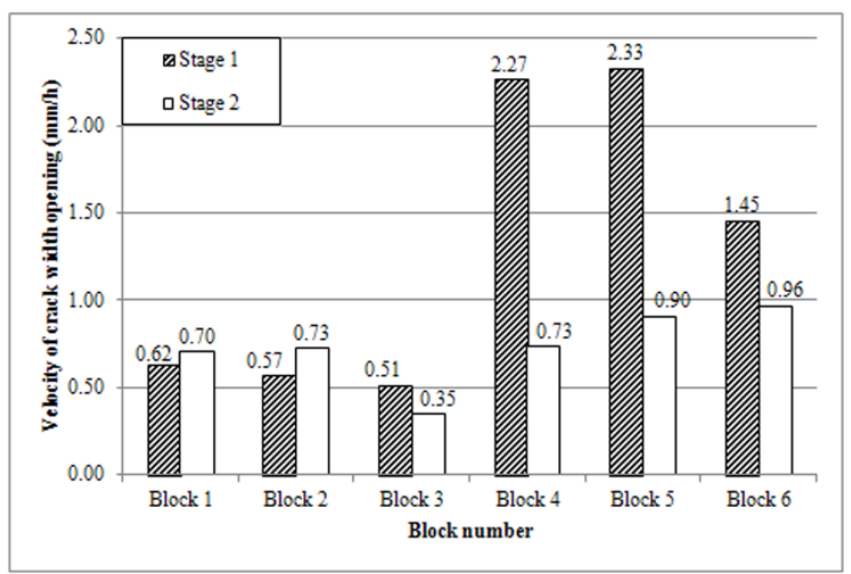

Fig.9 Velocities of cumulative crack width opening at Stage 1 and Stage 2 


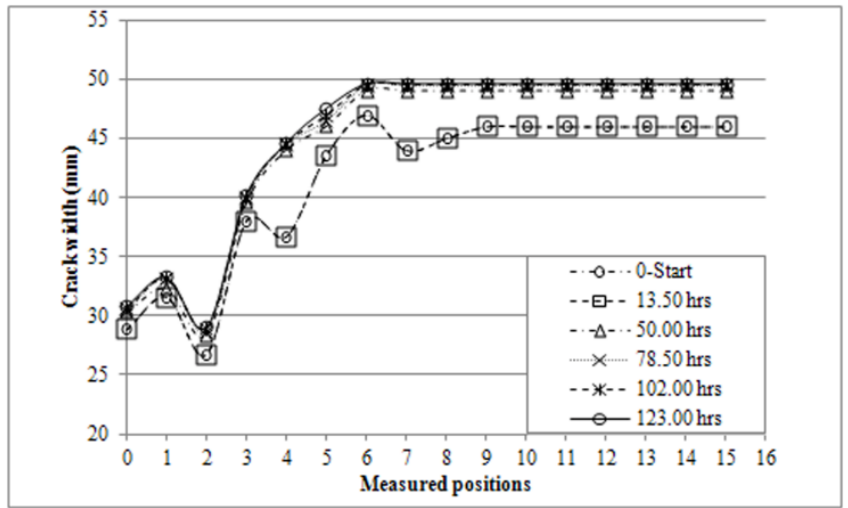

Fig.10a Distribution of cumulative crack width on sides - Type 1 Batch A Block 1

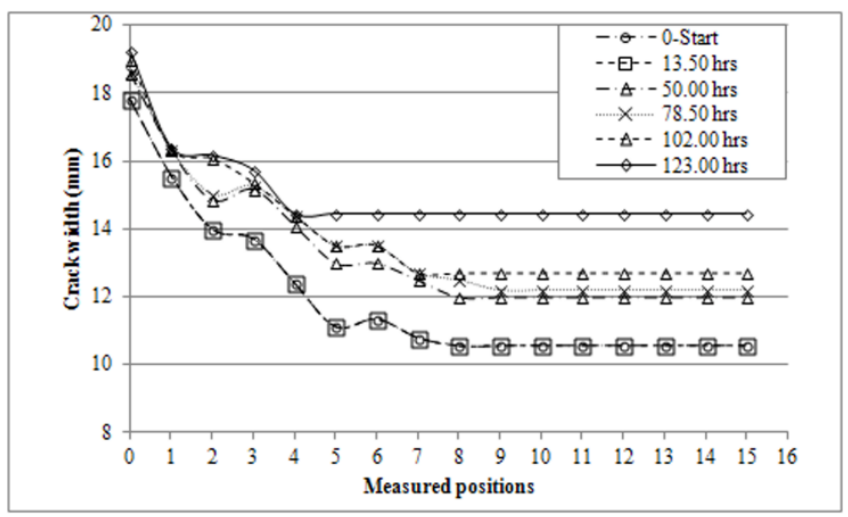

Fig.10b Distribution of cumulative crack width on sides - Type 2 Batch A Block 1

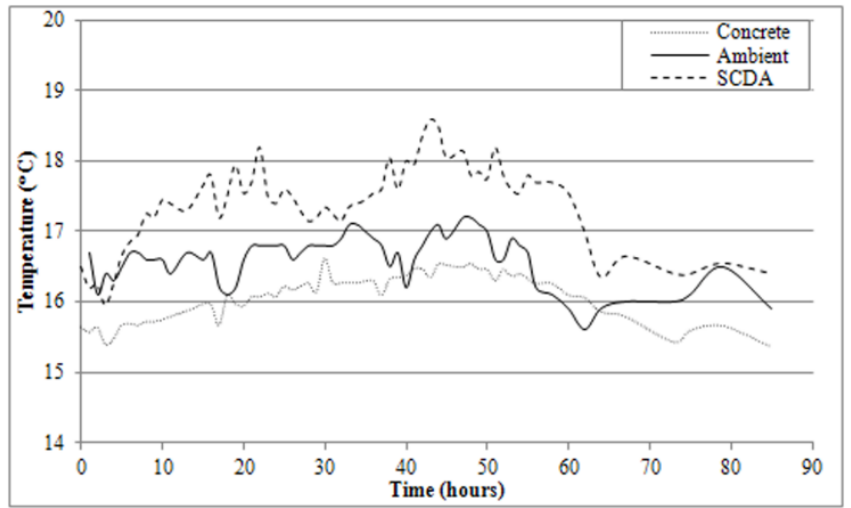

Fig.11 Variation of temperatures throughout the demolition process - Batch B Block 4 


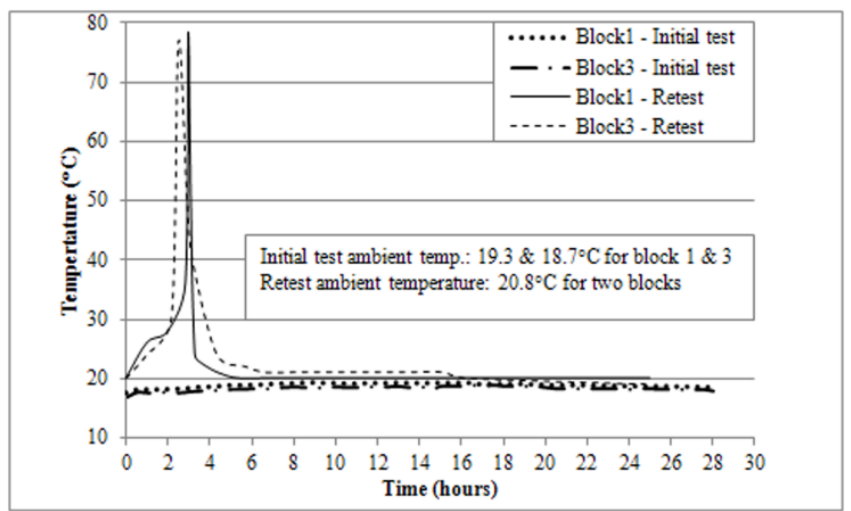

Fig.12 SCDA temperature inside the hole - Re-testing through SCDA reapplication

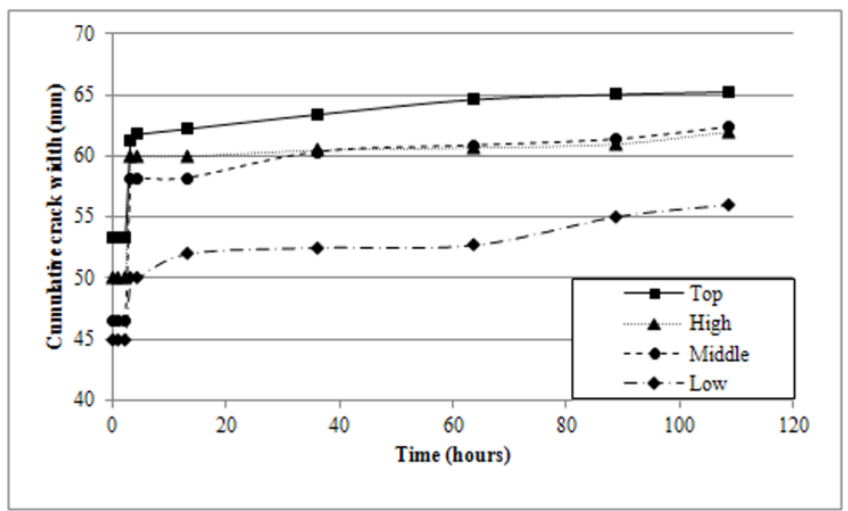

Fig.13 Cumulative crack width opening at the second pour with plastic cover inner the hole surface - Batch A Block 3

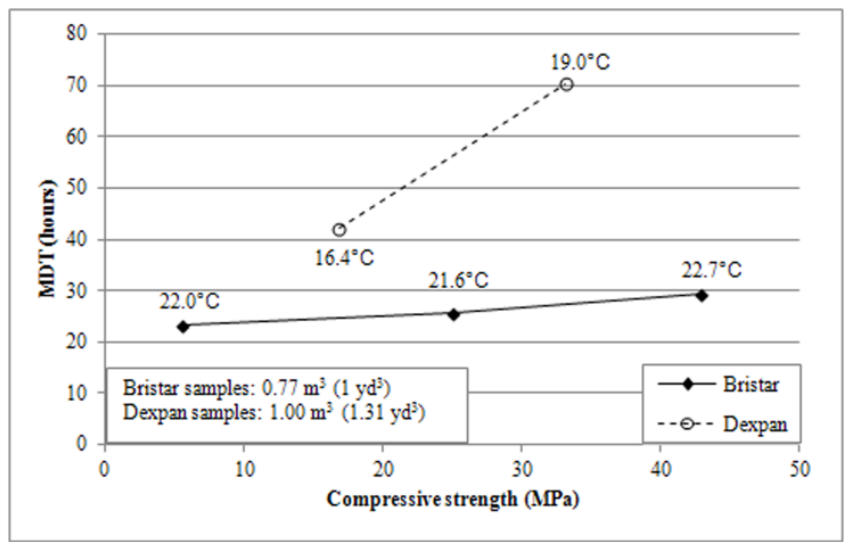

Fig.14 Trend of MDT versus material strength [Data of Bristar from (Bristar, 2016)] 


\section{References}

Bristar. Taiheiyo Material Company: Product Overview [Online]. Available: http://www.taiheiyo-m.co.jp/ (Accessed 20/5/2016)

Candlot, M. (1890) 'Bul. Soc. d'Encouragement pour l'Industrie Nationale 682'

Candlot, M. (1906) 'Ciments et chaux hydrauliques', Fabrication, propriétés, emploi. Paris: Librairie Polytechnique.

Cohen, M. D. (1983a) 'Modeling of expansive cements', Cement and Concrete Research, Vol. 13, pp.519-528.

Cohen, M. D. (1983b) 'Theories on expansion in sulfoaluminate - type expansive cements: Schools of thought', Cement and Concrete Research, Vol. 13, pp.809818.

Cohen, M. D., Olek, J. \& Mather, B. (1991) 'Silica fume improves expansive-cement concrete', Concrete International, Vol. 13, pp.31-37.

Cohen, M. D. \& Richards, C. W. (1982) 'Effects of particle sizes of expansive clinker of type K expansive cements', Cement and Concrete Research, Vol. 12, pp.717725.

Dexpan. Archer Company USA Inc: Product Overview [Online]. Available: http://demolition-contractor-rockbreaker-jackhammer.com/ (Accessed 20/5/2016)

Dowding, C. H. \& Labuz, J. F. (1982) 'Fracturing of rock with expansive cement', ASCE Journal of Geotechnical Engineering, Vol. 108, pp.1288-1299.

Gambatese, J. A. (2003) 'Controlled concrete demolition using expansive cracking agents', ASCE Journal of construction engineering and management, Vol. 129, pp. 98-104.

Gani, M. S. J. (1997) Cement and concrete, London, Chapman \& Hall.

Gómez, C. \& Mura, T. (1984) 'Stresses caused by expansive cement in borehole', Journal of Engineering Mechanics, Vol. 110, pp.1001-1005.

Hinze, J. \& Bown, J. (1994) 'Properties of soundless chemical demolition agents', ASCE Journal of Construction Engineering and Management, Vol. 120, pp.816-827.

Hinze, J. \& Nelson, A. (1996) 'Enhancing performance of soundless chemical demolition agents', ASCE Journal of construction engineering and management, Vol. 122, pp.193-195.

Huynh, M. P. \& Laefer, D. F. (2009) 'Expansive cements and soundless chemical demolition agents: state of technology review' in: Proceedings of The 11th conference on science and technology, Ho Chi Minh, Vietnam, pp.209-214. 
Laefer, D. F., Ambrozevitch-Cooper, N., Huynh, M. P., Midgette, J., Ceribasi, S. \& Wortman, J. (2010) 'Expansive fracture agent behaviour for concrete cracking', Magazine of Concrete Research, Vol. 62, pp.443-452.

Michaelis, W. (1892) 'Der zementbazillus', Tonindustrie Zeitung, Vol. 16, pp.15.

Natanzi, A., Laefer, D. \& Connolly, L. (2016a) 'Cold and moderate ambient temperatures effects on expansive pressure development in soundless chemical demolition agents', Construction and Building Materials, Vol. 110, pp.117-127.

Natanzi, A.S., Laefer, D.F, Mullane, S. (2016b). "Chemical Demolition of Unit Masonry: a Preparatory Study" Tenth International Conference on Structural Analysis of Historical Constructions: Anamnesis, Diagnosis, Therapy, Controls (SAHC2016), Leuven, Belgium, pp. 88-95.

Neville, A. M. (1981) Properties of concrete, London, Pitman.

Soeda, K., Hayashi, H., Hida, T. \& Tsuchiya, K. (1993) 'Fast-acting non-explosive demolition agent' in: Proceedings of the Third International RILEM Symposium: Demolition and Reuse of Concrete Masonry, Odense, Denmark, pp.243-254.

Timoshenko, S. P. \& Goodier, J. N. (1970) Theory of Elasticity, Tokyo, McGraw-Hill Kogakusha. 